NBER WORKING PAPER SERIES

\title{
AGGREGATE EMPLOYMENT FLUCTUATIONS WITH MICROECONOMIC ASYMMETRIES
}

Jeffrey R. Campbell

Jonas D. M. Fisher

Working Paper 5767

\author{
NATIONAL BUREAU OF ECONOMIC RESEARCH \\ 1050 Massachusetts Avenue \\ Cambridge, MA 02138 \\ September 1996
}

We thank Hugo Hopenhayn for helpful conversations. The comments of seminar participants at Carnegie-Mellon, Federal Reserve Bank of Minneapolis, and the Impulses and Propagation Mechanisms group meeting at the 1996 NBER Summer Institute are also appreciated. Part of the work for this paper was completed while we were visiting the Institute for Empirical Macroeconomics and we thank the Institute for its hospitality during this time. Fisher thanks the Social Sciences and Humanities Research Council for financial support. Any opinions expressed are those of the authors and not necessarily those of the Federal Reserve Bank of Chicago, the Federal Reserve System, or the National Bureau of Economic Research. This paper is part of NBER's research program in Economic Fluctuations and Growth.

C 1996 by Jeffrey R. Campbell and Jonas D. M. Fisher. All rights reserved. Short sections of text, not to exceed two paragraphs, may be quoted without explicit permission provided that full credit, including $(\mathcal{C}$ notice, is given to the source. 


\title{
AGGREGATE EMPLOYMENT FLUCTUATIONS WITH MICROECONOMIC ASYMMETRIES
}

\begin{abstract}
We provide a simple explanation for the observation that the variance of job destruction is greater than the variance of job creation: job creation is costlier at the margin than job destruction. As Caballero [2] has argued, asymmetric employment adjustment costs at the establishment level need not imply asymmetric volatility of aggregate job flows. We construct an equilibrium model in which (S,s)-type employment policies respond endogenously to aggregate shocks. The microeconomic asymmetries in the model can dampen the response of total job creation to an aggregate shock and cause it to be less volatile than total job destruction. This is so even though aggregate shocks are symmetrically distributed.
\end{abstract}

Jeffrey R. Campbell

Department of Economics

Harkness Hall

University of Rochester

Rochester, NY 14627

and NBER

jyrc@troi.cc.rochester.edu
Jonas D. M. Fisher

Research Department

Federal Reserve Bank of Chicago

230 South La Salle Street

Chicago, IL 60604 


\section{Introduction}

In this paper we provide a simple explanation for the observation documented by Davis and Haltiwanger $[7,8]$ that the variance of job destruction is greater than the variance of job creation: job creation is costlier at the margin than job destruction. As Caballero [2] has argued, asymmetric employment adjustment costs at the establishment level need not imply asymmetric volatility of aggregate job flows. We construct an equilibrium model in which $(S, s)$-type employment policies respond endogenously to aggregate shocks. Contrary to Caballero [2], we find that microeconomic asymmetries can dampen the response of job creation to an aggregate shock and cause it to be less volatile than job destruction.

The employment policies we consider are ones for which an establishment keeps employment constant if it lies within a range determined by its idiosyncratic level of technology. If employment is initially above this range it is reduced to the range's upper boundary, and if it is below it is increased to the lower boundary. The difference between our results and Caballero's [2] lies in how the 'range of inaction' responds to aggregate disturbances. If we assume its boundaries respond equally in percentage terms to aggregate disturbances, then total job creation and destruction will change by similar amounts. ${ }^{1}$ In this case creation and destruction will be, roughly, equally variable, as in Caballero [2]. However, if we solve for the optimal response of the boundaries, job creation costs can cause the lower boundary to be less elastic with respect to an aggregate disturbance than the upper boundary. Because the level to which job destroyers reduce their employment changes by more than the level to which job creators increase their employment, total job destruction can respond proportionately by more than creation, leading to the former being more variable than the latter.

The asymmetric volatility of aggregate job flows is closely tied to another fact documented by Davis and Haltiwanger which has received considerable attention in the literature. Namely, the observation that job reallocation, the sum of job creation and job destruction, is countercyclical. The algebraic identities linking job growth (job creation less job destruc-

\footnotetext{
${ }^{1}$ Here we are implicitly assuming sufficient variability in idiosyncratic technology and symmetric aggregate disturbances.
} 
tion) and reallocation to job creation and destruction imply that job reallocation co-varies negatively with job growth if and only if job destruction is more volatile than job creation. Thus our explanation for asymmetric volatility in aggregate job flows can be added to the list of potential explanations for countercyclical job reallocation. ${ }^{2}$

Our analysis builds on Hopenhayn's [11] industry dynamics model of establishment size. This is a natural starting point because the job creation and destruction data reflect establishment growth and contraction. Anderson and Meyer [1] document large differences between match creation and destruction and job creation and destruction. This suggests an advantage of our approach to understanding the phenomena documented by Davis and Haltiwanger relative to other approaches which focus on the job matching process.

The remainder of the paper proceeds as follows. In the next section we present the industry dynamics model and characterize stationary and dynamic equilibria. In section three we analyze several parametric examples of the model to illustrate the impact on aggregate variables of asymmetric employment adjustment costs at the establishment level. We conclude in the fourth section by relating our findings to other attempts in the literature to account for the behavior of aggregate job flows.

\section{The Industry Dynamics Model}

We extend Hopenhayn's [11] industry dynamics model to incorporate linear job creation costs and uncertainty about labor supply. A key feature of the model that makes it tractable to analyze is the assumption of unrestricted entry into the industry. As we describe below, this assumption removes the probability distribution of establishments as a state variable in the problems of individual agents, drastically lowering the computational complexity involved in solving the model. We begin by describing the model environment. This is followed by a description of the problem of a representative establishment owner in the industry. After this we define a competitive equilibrium and characterize stationary equilibria and equilibria with aggregate uncertainty.

\footnotetext{
${ }^{2}$ See for example Caballero and Hammour [4] and Mortensen and Pissarides [13] who emphasize the role of the job matching process in generating this phenomenon. Campbell and Kuttner [6] and Davis and Haltiwanger [9] interpret counter-cyclical job reallocation as reflecting the influence of 'reallocation shocks.'
} 


\subsection{The Model Environment}

The model's industry consists of a continuum of establishments which each produce a single, non-storable good for sale in a competitive market. Aggregate demand for the good in period $t$, is a given by $P_{t}^{\gamma}$, where $P_{t}$ is the market price and $\gamma<0$ is the elasticity of demand. Each establishment produces output using labor as its only variable input. We assume the industry is a small portion of the economy so that the wage rate, $W_{t}$, is exogenous. It follows a Markov chain over the grid $\left\{W^{l}, W^{h}\right\}$ and is the only source of industry-wide, or aggregate, uncertainty.

Output of a representative establishment at time $t$ depends on its time $t$ productivity and labor input, $z_{t}$ and $n_{t}$, respectively, and is given $b^{3}{ }^{3}$

$$
q_{t}=z_{t} n_{t}^{\alpha}, \quad 0<\alpha<1
$$

The diminishing returns to labor reflect the presence of a fixed factor which can be thought of as a plant. We assume that the shift length is fixed so that $n_{t}$ can be interpreted as employment. For each establishment, productivity evolves as follows,

$$
\ln z_{t}=\rho_{z} \ln z_{t-1}+e_{t}, \quad e_{t} \sim \mathbf{N}\left(0, \sigma_{z}^{2}\right), \quad\left|\rho_{z}\right|<1
$$

Entry to the industry is unrestricted and potential entrants face a cost of creating a new establishment, $\kappa$. When a new establishment is born, it draws its initial value of productivity from a continuous distribution with p.d.f. $\lambda(\cdot)$. Establishment owners face an exit decision every period. When making this decision they take into account the scrap value of an establishment, $\theta<\kappa$. The decision to close an establishment is irreversible. Establishment owners are identical, risk neutral, and discount future profits with a common rate, $\beta$.

The owner of an establishment incurs an adjustment cost if it expands its employment. Since new establishments begin life with no employees, they must always incur this adjust-

\footnotetext{
${ }^{3}$ Our notational convention is to use upper case to denote aggregate variables, lower case to denote establishment level variables and Greek letters to denote parameters.
} 
ment cost. If $n_{t}$ is an establishment's previous employment, its job creation costs are

$$
\tau\left(n_{t}-n_{t-1}\right) I\left\{n_{t}>n_{t-1}\right\}
$$

where $\tau>0$ is the per job creation cost. The function $I\{\cdot\}$ equals one if its argument is true and zero otherwise. We interpret these job creation costs as reflecting the costs of reorganizing the tasks performed in a establishment to accommodate a larger work force.

\subsection{The Establishment Owner's Problem}

At the beginning of a period, the owner of an establishment observes its productivity, $z_{t}$, and the output and input prices, $P_{t}$ and $W_{t}$. On the basis of this information, employment at each establishment is chosen. At the end of the period, owners must decide whether or not to close their establishments. Let $S_{t}$ denote a vector of payoff relevant aggregate variables. It will include the cuurent output and input prices, $P_{t}$ and $W_{t}$, as well as any other variables which aid in forecasting their future values. Then, the value of a typical establishment at time $t, v\left(z_{t}, n_{t-1}, S_{t}\right)$, satisfies the following Bellman equation,

$$
\begin{aligned}
v\left(z_{t}, n_{t-1}, S_{t}\right)= & \max _{n_{t} \geq 0} P_{t} z_{t} n_{t}^{\alpha}-W_{t} n_{t}-\tau\left(n_{t}-n_{t-1}\right) I\left\{n_{t}>n_{t-1}\right\} \\
& +\beta \max \left\{\theta, \mathbf{E}\left[v\left(z_{t+1}, n_{t}, S_{t+1}\right) \mid z_{t}, S_{t}\right]\right\}
\end{aligned}
$$

In solving its dynamic program, the establishment owner is assumed to know the underlying law of motion for $S_{\ell}$. We now discuss the optimal employment and exit policies which correspond to the solution to the establishment owner's problem.

As is well known, it is optimal in the presence of linear adjustment costs to follow an $(S, s)$ type policy. To characterize the employment policy for the present case, let $f^{+}\left(z_{t}, n_{t}, S_{t}\right)$ denote the right derivative of $\beta \max \left\{\theta, \mathrm{E}\left[v\left(z_{t+1}, n_{t}, S_{t+1}\right) \mid z_{t}, S_{t}\right]\right\}$ with respect to $n_{t}$, and let $f^{-}\left(z_{t}, n_{t}, s_{t}\right)$ denote the left derivative. Then, the necessary conditions for the owner's employment decision are

$$
\alpha P_{t} z_{t} n_{t}^{\alpha-1}-W_{t}-\tau+f^{-}\left(z_{t}, n_{t}, S_{t}\right) \leq 0 \text { if } n_{t} \geq n_{t-1}
$$




$$
\alpha P_{t} z_{t} n_{t}^{\alpha-1}-W_{t}+f^{+}\left(z_{t}, n_{t}, S_{t}\right) \geq 0 \text { if } n_{t} \leq n_{t-1}
$$

If $n_{t}>n_{t-1}$, then equation (2) must hold with equality, and if $n_{t}<n_{t-1}$, then equation (3) must hold with equality. Define $\underline{n}_{t}\left(z_{t}\right)$ and $\bar{n}_{t}\left(z_{t}\right)$ as the values of $n_{t}$ which satisfy equations (2) and (3), respectively, with equality, for each possible value of $z_{t}$. The dependence of these functions on $t$ is our notational shorthand for the fact that they depend on the aggregate state $S_{t}$. The optimal employment policy now can be written as

$$
n_{t}\left(z_{t}, n_{t-1}\right)= \begin{cases}\underline{n}_{t}\left(z_{t}\right), & \text { if } n_{t-1} \leq \underline{n}_{t}\left(z_{t}\right) \\ n_{t-1}, & \text { if } \underline{n}_{t}\left(z_{t}\right)<n_{t}<\bar{n}_{t}\left(z_{t}\right) . \\ \bar{n}_{t}\left(z_{t}\right), & \text { if } \bar{n}_{t}\left(z_{t}\right) \leq n_{t-1}\end{cases}
$$

Below we refer to $\underline{n}_{t}\left(z_{t}\right)$ as the date $t$ job creation schedule since it indicates the employment levels of job creating establishments. Similarly, we refer to $\bar{n}_{t}\left(z_{t}\right)$ as the job destruction schedule.

Just as in Hopenhayn [11], a threshold rule characterizes the owner's exit decision. This is explained as follows. Notice first that the unique solution to (1) must be increasing in $z_{t}$, which implies that $\mathbf{E}\left[v\left(z_{t+1}, n_{t}, S_{t+1}\right) \mid z_{t}, S_{t}\right]$ is increasing in $z_{t}$. Thus there exists a threshold value, $x_{t}\left(n_{t}\right)$,

$$
x_{t}\left(n_{t}\right)=\sup \left\{z \mid \mathrm{E}\left[v\left(z_{t+1}, n_{t}, S_{t+1}\right) \mid z_{t}=z, S_{t}\right] \leq \theta\right\},
$$

such that all establishments with employment equal to $n_{t}$ and $z_{t} \leq x_{t}\left(n_{t}\right)$ will exit, and all others will remain. The exit threshold in general depends on the aggregate state which we again summarize with the subscript $t$.

\subsection{Competitive Equilibrium}

In order to define a competitive equilibrium it remains to describe entry, aggregate quantities and the transition rule for the distribution of establishments across productivity and employment levels. Consider entry first. Because entry is unrestricted, the expected value 
of an entering establishment must be less than or equal to its cost, $\kappa$, for all $S_{t}$. That is,

$$
\int v\left(z_{t}, 0, S_{t}\right) \lambda\left(z_{t}\right) d z_{t} \leq \kappa \quad \forall S_{t}
$$

If any entry occurs during period $t$, then (6) must hold with equality. We use $B_{t}$ to denote the mass of new entrants, or births, at time $t$.

Total industry labor input and output, $N_{t}$ and $Q_{t}$, respectively, are defined as follows,

$$
\begin{aligned}
N_{t} & =\iint n_{t} G_{t}\left(z_{t}, n_{t}\right) d z_{t} d n_{t} \\
Q_{t} & =\iint q_{t} G_{t}\left(z_{t}, n_{t}\right) d z_{t} d n_{t}
\end{aligned}
$$

Here $G_{t}(\cdot, \cdot)$ summarizes the measure of establishments across all possible pairs of productivity and employment levels at time $t$.

The employment policy, (4), endows $G_{t}$ with certain properties. First, it implies that $G_{t}\left(z_{t}, n_{t}\right)=0$ if $n_{t}<\underline{n}_{t}\left(z_{t}\right)$ or if $n_{t}>\bar{n}_{t}\left(z_{t}\right)$. Second, it implies a positive fraction of establishments will be on the schedules defined by $\underline{n}_{t}\left(z_{t}\right)$ and $\bar{n}_{t}\left(z_{t}\right)$. Therefore, $G_{t}\left(z_{t}, n_{t}\right)$ can be written in terms of three functions, $\underline{G}_{t}\left(z_{t}\right), \bar{G}_{t}\left(z_{t}\right)$ and $G_{t}^{m}\left(z_{t}, n_{t}\right)$,

$$
G_{\iota}\left(z_{t}, n_{t}\right)= \begin{cases}\underline{G}_{t}\left(z_{t}\right), & \text { if } n_{t}=\underline{n}\left(z_{t}\right) \\ G_{t}^{m}\left(z_{t}, n_{t}\right), & \text { if } \underline{n}_{t}\left(z_{t}\right)<n_{t}<\bar{n}_{t}\left(z_{t}\right) \\ \bar{G}_{t}\left(z_{t}\right), & \text { if } n_{t}=\bar{n}_{t}\left(z_{t}\right)\end{cases}
$$

The owner's employment, entry, and exit decisions determine the transition rule for $G_{t}$. The presentation of this transition rule is straightforward but tedious, and so is left to appendix A.

In a competitive equilibrium, all potential entrants are either indifferent to entering or strictly prefer to stay out of the industry, all of the industry's establishment owners choose employment and make exit decisions to maximize the present discounted value of their expected profits, and both the product and labor markets clear. The following definition summarizes this more formally.

Definition 1 (Competitive Equilibrium). A competitive equilibrium for the industry 
is a set of state contingent sequences $\left\{P_{t}^{*}\right\},\left\{Q_{t}^{*}\right\},\left\{N_{t}^{*}\right\},\left\{B_{t}^{*}\right\},\left\{n_{t}^{*}\left(z_{t}, n_{t-1}\right)\right\},\left\{x_{t}^{*}\left(n_{t}\right)\right\}$, and $\left\{G_{t}^{*}\left(z_{t}, n_{t}\right)\right\}$ and a value function $v^{*}\left(z_{t}, n_{t-1}, S_{t}^{*}\right)$ such that for all $t$

1. $Q_{t}^{*}=P_{t}^{* \gamma}$.

2. $v^{*}\left(z_{t}, n_{t-1}, S_{t}^{*}\right)$ is the unique solution to (1) given the stochastic process for $S_{t}^{*}=$ $\left(P_{t}^{*}, W_{t}^{*}, G_{t}^{*}\left(z_{t}, n_{t}\right)\right)$.

3. $n_{t}^{*}\left(z_{t}, n_{t-1}\right)$ is defined as in (4).

4. $x_{t}^{*}\left(n_{t}\right)$ is defined as in (5).

5. $N_{t}^{*}$ is defined as in (7).

6. $Q_{t}^{*}$ is defined as in (8).

7. The free entry condition, (6), holds in every possible state. It holds with equality in any state where $B_{t}^{*}>0$.

8. $G_{t}^{*}\left(z_{t}, n_{t}\right)$ is defined recursively as in appendix $A$.

Hopenhayn [11] shows that a competitive equilibrium exists and is unique in a similar industry dynamics model without aggregate uncertainty. Before proceeding to the characterization of the competitive equilibrium with aggregate uncertainty, it is helpful to first study the model's steady state, an equilibrium in which all prices and aggregate quantities are constant.

\subsection{The Steady State}

Consider a version of the above model in which the wage rate equals some constant, $W^{*}$. A stationary equilibrium for this model is a competitive equilibrium in which all other aggregate prices and quantities are also constant. We can compute the stationary equilibrium as follows. First consider the solution to (1) given the constant wage and some constant output price, $P$. Since $v\left(z_{t}, n_{t-1}, S_{t}\right)$ is continuous and strictly increasing in $P, u(P)=\int v\left(z_{t}, 0, S_{t}\right) \lambda\left(z_{t}\right) d z_{t}$ is also. Because $u(0)=0$ and $\lim _{P \rightarrow \infty} u(P)=\infty$, there must exist a unique $P^{*}$ such that 
$u\left(P^{*}\right)=\kappa$. This is the unique stationary equilibrium output price. From the associated solution to (1) the stationary equilibrium employment and exit policies, $n^{*}\left(z_{t}, n_{t-1}\right)$ and $x^{*}\left(n_{t}\right)$, can be derived.

Given the owner's stationary equilibrium policies and a value for entry, $B$, we can find a fixed point of the transition equation for the measure of establishments over productivity and employment. Denote this $G\left(z_{t}, n_{t}\right)$. It is straightforward to show that $G\left(z_{t}, n_{t}\right)$ is linear in $B$, which, via (8), implies output is linear in $B$ also. The equilibrium volume of entry, $B^{*}$, is easily found by solving for the value of $B$ which equates industry supply with the quantity demanded at the previously arrived at output price, $P^{* \gamma}$. With $B^{*}$ in hand, $G^{*}\left(z_{t}, n_{t}\right), Q^{*}$, and $N^{*}$ can be computed.

Notice that because $G\left(z_{t}, n_{t}\right)$ is a linear function of entry, $B^{*}$ only determines the industry's scale. It does not influence the probability distribution of establishments across productivity and employment levels. In the stationary equilibrium analysis of Hopenhayn [11], this distribution is the primary object of interest. Because the establishment owner is a price taker, the demand elasticity $\gamma$ does not effect the solution of her dynamic programming problem in a stationary equilibrium. Therefore, $\gamma$ only affects the industry's scale also.

\subsection{Equilibrium with Aggregate Uncertainty}

We can construct an equilibrium of the model with a stochastic wage rate in much the same way as for a stationary equilibrium. The key once again is the free entry condition, (6). If the volume of entry is always positive, then the free entry condition must always be satisfied with equality. In this case, the equilibrium price sequence is uniquely determined by the stochastic process for the wage, the owner's dynamic programming problem, and the free entry condition. This simplifies the analysis considerably because it implies it is not necessary to include $G_{t}$ as an argument in the establishment owner's policy functions. ${ }^{4} \mathrm{We}$ now describe how to solve the model with aggregate uncertainty in more detail.

Suppose that $B_{t}$ is always strictly positive in equilibrium and that the output price is a function of the current wage only. Because the wage takes on one of two values, so must the

\footnotetext{
${ }^{4}$ Caballero and Hammour [3] use a similar argument to solve their model of job creation and destruction.
} 
price. Let $P^{l}$ and $P^{h}$ be the output prices when the wage equals $W^{l}$ and $W^{h}$, respectively. When the output price follows this stochastic process, the solution to the owner's dynamic programming problem can be written as the pair of functions $v^{l}\left(z_{t}, n_{t-1}\right)$ and $v^{h}\left(z_{t}, n_{t-1}\right)$. These are the solutions to (1) when the wage is $W^{l}$ and $W^{h}$, respectively. Given these functions, one can compute the value of entry in the two states as a function of the prices:

$$
u^{l}\left(P^{l}, P^{h}\right)=\int v^{l}\left(z_{t}, 0\right) \lambda\left(z_{t}\right) d z_{t} \text { and } u^{h}\left(P^{l}, P^{h}\right)=\int v^{h}\left(z_{t}, 0\right) \lambda\left(z_{t}\right) d z_{t}
$$

Unrestricted entry drives profits to zero so we can use (6) holding with equality to find candidate equilibrium prices. That is, candidates for equilibrium prices solve the following system of two non-linear equations in two unknowns,

$$
\begin{aligned}
& u^{l}\left(P^{l *}, P^{h *}\right)=\kappa, \\
& u^{h}\left(P^{l *}, P^{h *}\right)=\kappa .
\end{aligned}
$$

Given these prices it is possible to compute quantities sequentially for any given realization of the process $\left\{W_{t}\right\}$ and an initial condition for the industry. $G_{0}\left(z_{0}, n_{0}\right)$. To see this, suppose that in the first period. $W_{1}=W^{l}$, so that the candidate equilibrium price for the first perod is $P_{1}=P^{l}$. Since the transition rule for $G_{t}$, in the appendix, implies that $G_{1}\left(z_{1}, n_{1}\right)$ is an increasing function of entry, (8) implies that the total quantity produced by the industry's establishments at $P_{1}$ also is an increasing function of entry. Write this relationship as $Q_{1}(B)$. In the competitive equilibrium, the volume of entry must be exactly that which clears the market for the industry's good. So a candidate for equilibrium entry in the first period, $B_{1}$, solves

$$
Q_{1}\left(B_{1}\right)=P_{1}^{\gamma}
$$

With $B_{1}$ in hand, one can compute $G_{1}\left(z_{1}, n_{1}\right)$ and any aggregate variable of interest. The analogous procedure applies to future quantities.

The candidate equilibrium for a given sequence of wages will be a genuine equilibrium as long as entry is strictly positive in every period. So, for example, if $Q_{1}(0)>P_{1}^{\gamma}$ then the constructive procedure fails. However, if the model has a stationary equilibrium with 
$B^{*}>0$ and the support of $W_{t}$ is narrow enough, the assumption that $B_{t}$ is always strictly positive should be satisfied. In appendix B we study a version of the model with aggregate uncertainty but without job creation costs in which strictly positive entry is guaranteed to hold. Using homotopy ideas we can expect versions of our model with positive job creation costs to involve strictly positive entry as well. Indeed, in the simulations conducted for the analysis in the next section entry is always strictly positive.

\section{Job Creation Costs and Aggregate Employment Fluctuations}

In this section we investigate the implications of job creation costs in our model. When job creation costs are positive then we find that job destruction may be more volatile than job creation. To build intuition for this finding, it is useful to consider a version of our model where $\beta=0$. In such a model, establishments' employment decisions are entirely static and analytical expressions for the job destruction and creation schedules, $\bar{n}_{t}\left(z_{t}\right)$ and $\underline{n}_{t}\left(z_{t}\right)$, respectively, can be derived:

$$
\underline{n}_{t}\left(z_{t}\right)=\left(\frac{W_{t}+\tau}{\alpha P_{t} z_{t}}\right)^{\frac{1}{\alpha-1}} \text { and } \bar{n}_{t}\left(z_{t}\right)=\left(\frac{W_{t}}{\alpha P_{t} z_{t}}\right)^{\frac{1}{\alpha-1}}
$$

Now consider how these schedules respond to exogenous changes in the wage rate. The relevant elasticities are,

$$
\frac{\partial \ln \left(\underline{n}_{t}\left(z_{t}\right)\right)}{\partial \ln W_{t}}=\frac{1}{\alpha-1} \times \frac{W_{t}}{W_{t}+\tau} \quad \text { and } \quad \frac{\partial \ln \left(\bar{n}_{t}\left(z_{t}\right)\right)}{\partial \ln W_{t}}=\frac{1}{\alpha-1}
$$

Clearly, as long as job creation costs are positive, the job destruction schedule is more elastic with respect to the wage than the job creation schedule. In response to a wage disturbance the level to which job destroyers reduce their employment will vary by more than the level to which job creators increase their employment. Other things equal, the larger the creation cost, the greater the discrepancy between how much total job creation changes relative to total job destruction. If dynamic considerations do not overcome these purely static effects, then the foregoing suggests that we have some hope of accounting for the excess volatility of job destruction with our model. 
The arguments in Caballero [2] should caution us in drawing conclusions about aggregate variables from underlying microeconomic behavior. As he has forcefully argued, the evolution of the underlying distribution of establishments can have significant effects on aggregate variables and lead them to behave very differently than establishment level variables. This makes it crucial for us to simulate the model to derive its implications for aggregate employment fluctuations. In the rest of this section we describe the results of doing this for several different parameterizations. We begin by describing the main parameter selections which underlie our simulations. This is followed by a brief discussion of the implied steady state of the model which is designed to shed light on the empirical plausibility of our parameter selections. Finally, we discuss the simulation results. ${ }^{5}$

\subsection{Parameter Values}

The examples we consider share the same stationary equilibrium. In table 1 we list the parameters which underlie this equilibrium. For the most part these parameters were chosen so that statistics derived from the implied stationary equilibrium resemble selected statistics reported by Davis and Haltiwanger [8] for the US manufacturing sector. Specifically, we attempt to match the average rate of job destruction as well as the average employment weighted entry and exit rates. ${ }^{6}$ We use the variance of the innovation to technology, $\sigma_{z}$, the scrap value, $\theta$, and the support of the distribution for new entrants' productivity to accomplish this. We follow Hopenhayn and Rogerson [12] in specifying the distribution of new entrants' productivity, $\lambda(\cdot)$. It is assumed to be uniform with support that ranges

\footnotetext{
${ }^{5}$ Details on the solution and simulation procedure are available from the authors if requested. The broad outlines of our procedure are as follows. We proceed in two steps. In the first step we solve for the equilibrium prices and in the second step we simulate using an approximation to the transition equation for $G$. To arrive at the equilibrium prices we have to solve the owner's Bellman equation. We do this by approximating the value function with a polynomial and then finding a fixed point in the parameters of the approximating polynomial. The solution to the Bellman equation implies employment and exit policies, which, as is described in appendix $\mathrm{A}$, determine the transition equation for $G$. We employ the method described in Campbell [5] to approximate the transition equation. Given an initial $G$, an approximate rule for updating $G$, and a sequence of pseudo-random wages, a sequence of $G$ 's can be generated. Using the constructive procedure described in section 2.5 an entry sequence can also be generated. Quantities of interest can then be computed directly from their definitions.

${ }^{6}$ Because the calculation of the stationary equilibrium is computationally intensive, a more formal procedure for parameter selection in which stationary equilibrium quantities are precisely matched with their empirical counterparts is currently infeasible.
} 


\begin{tabular}{|c|r|}
\hline Parameter & \multicolumn{1}{|c|}{ Value } \\
\hline$\kappa$ & 10 \\
$\theta$ & $0.98 \kappa$ \\
$\alpha$ & 0.64 \\
$\beta$ & $1.05^{-1 / 4}$ \\
$\tau$ & 0.5 \\
$\gamma$ & $-1 / 4$ \\
$\rho_{z}$ & 0.90 \\
$\sigma_{z}$ & 0.16 \\
\hline
\end{tabular}

Table 1: Baseline Parameter Values

from three standard deviations less than the mean of the unconditional distribution to some upper bound. By varying the upper bound we are able to improve our match with the stationary equilibrium statistics of interest. The support we use throughout the analysis is $\left[-3 \sigma_{z} / \sqrt{1-\rho_{z}^{2}}, \ln (1.4)\right]$.

Other parameters in table 1 are chosen on a priori grounds. The cost of entry, $\kappa$, is just a normalization so it has no consequence for the analysis. Labor's share in the production function, $\alpha$, is chosen to be consistent with other quantitative studies. We assume that the period length in the model is a quarter and that establishment owners discount future profits at an annualized rate of 5 per cent. This determines the discount rate, $\beta$. The autocorrelation of technology for establishments, $\rho_{z}$, is chosen to be consistent with the observation that there is substantial employment persistence in the manufacturing data. Of particular interest is the job creation cost, $\tau$. Since we normalize the steady state wage to unity, our selection of 0.5 for this parameter is equivalent to one half the quarterly wage in steady state. This does not seem exceptionally large to us. Finally, we use a demand elasticity of $1 / 4$. The selection of this parameter is governed by the need to ensure that along a given simulation entry always is strictly positive.

\subsection{Properties of the Stationary Equilibrium}

In the stationary equilibrium, the establishments' employment policies can be summarized by the job creation and destruction schedules, $\underline{n}_{0}\left(z_{t}\right)$ and $\bar{n}_{0}\left(z_{t}\right)$, and the exit policy $x_{0}\left(n_{t}\right)$. 


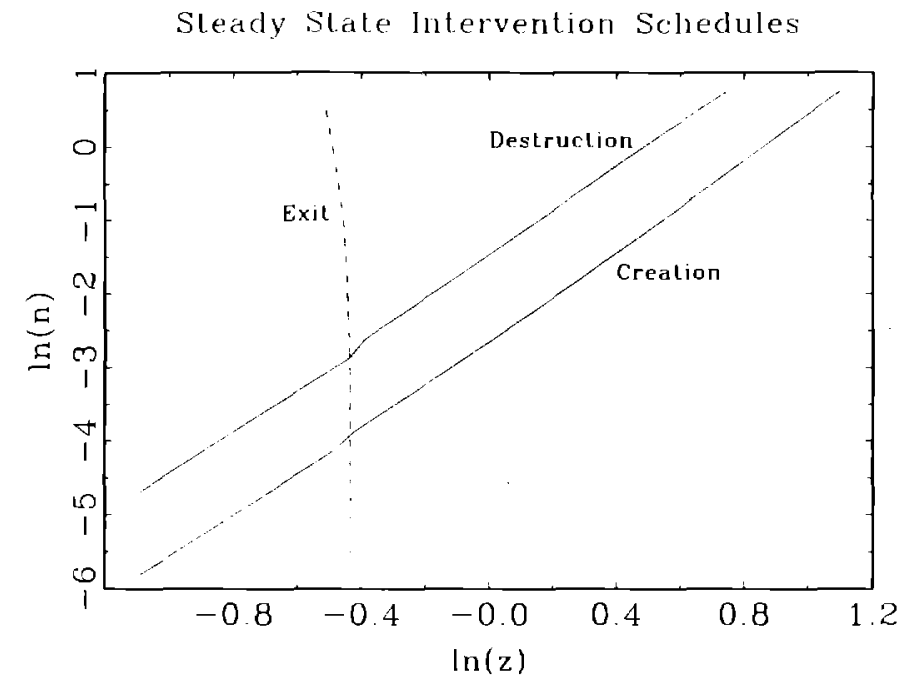

Figure 1: Establishment Policies $-\underline{n}_{0}\left(z_{t}\right), \bar{n}_{0}\left(z_{t}\right)$, and $x_{0}\left(n_{t}\right)$.

Figure 1 plots these using the parameter values in table 1. As this figure indicates, just as in the model without job creation costs, establishments' employment policies are nearly $\log$-linear in $z_{t}$. A clear exception to this is a discontinuity where each of the employment schedules cross the exit schedule. The exit schedule itself is nearly vertical, so establishments exit decisions vary little with their current employment.

The employment and exit policies determine the stationary equilibrium distribution of establishments across employment and productivity levels. The components of this distribution are plotted in figures 2 and 3. The panels of figure 2 graph the distribution of establishments along the destruction and creation schedules. These are $\bar{G}_{0}\left(z_{t}\right)$ and $\underline{G}_{0}\left(z_{t}\right)$ normalized by the total mass of establishments, respectively. Figure 3 plots cross-sections of $G^{m}\left(z_{t}, n_{t}\right)$ normalized by the total mass of establishments, the distribution in the region of inaction. Specifically, each curve in this figure indicates, for a given log employment level, the density in the region of inaction as a function of the log of technology.

The first point to note from the figures is that job creating establishments tend to be more productive than job destroying ones. The peak of $\underline{G}_{0}\left(z_{t}\right)$ is at a log technology level of about 0.35 , while the peak of $\bar{G}_{0}\left(z_{i t}\right)$ is at about -0.2 . Second, there is considerable mass 
Distribution on Destruction Schedule

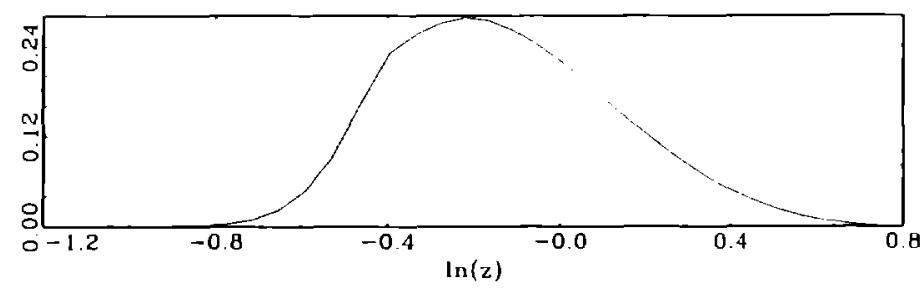

Distribution on Creation Schedule

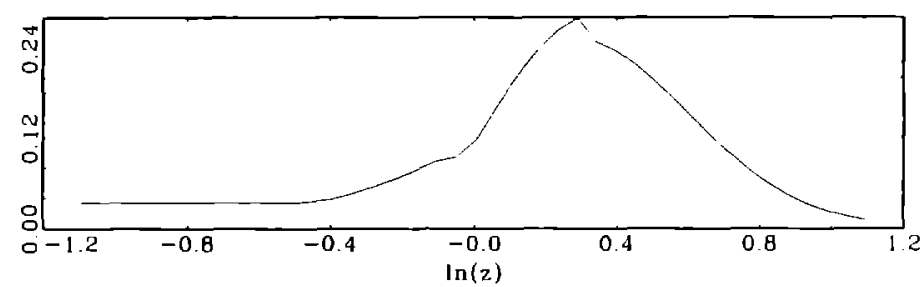

Figure 2: Stationary Equilibrium Distribution $-\bar{G}_{0}\left(z_{t}\right)$ and $\underline{G}_{0}\left(z_{t}\right)$

on both the job creation and destruction schedules. Establishments which lie on the job creation schedule account for $20.4 \%$ of total industry employment, and establishments which lie on the job destruction schedule account for $16.5 \%$ of employment. Third, the distribution within the region of inaction is discontinuous, reflecting the discontinuities in the creation and destruction schedules. Finally, the establishments that lie between the intervention schedules do not appear to be bunched up near one schedule or the other consistently throughout the state space. That is, with the exception of establishments that operate in the left hand tail of the productivity distribution, the density does not exhibit substantial asymmetry in the placement of mass near one employment policy relative to the other.

For the same parameter values, table 2 reports job creation and destruction statistics from the model's stationary equilibrium. In a stationary equilibrium, the job creation and destruction rates equal each other. The fact that they differ somewhat in table 2 reflects slight errors in our method of approximating the transition equation. Notice that the job creation and destruction rates in the stationary equilibrium are about $1 \%$ and $0.6 \%$ higher than their empirical counterparts. Therefore, the job reallocation rate is about $1.6 \%$ higher than the average job reallocation rate in the US manufacturing sector. The employment 
Distribution Within Region of Inaction

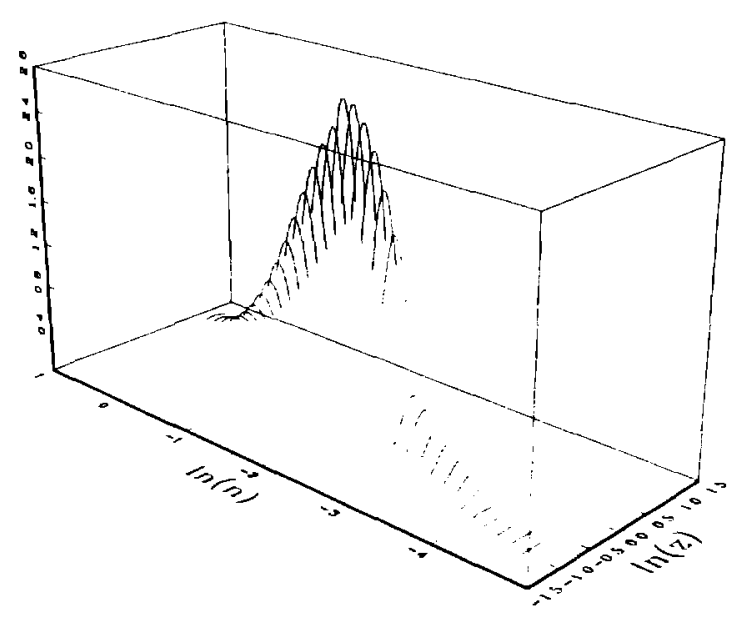

Figure 3: Stationary Equilibrium Distribution $-G^{m}\left(z_{t}, n_{t}\right)$

\begin{tabular}{|l|rr|}
\hline Statistic & Data & Model \\
\hline Job Creation & 5.39 & 6.34 \\
Job Destruction & 5.72 & 6.38 \\
Job Reallocation & 11.11 & 12.72 \\
Entry & 0.61 & 0.81 \\
Exit & 0.82 & 0.49 \\
\hline
\end{tabular}

Table 2: Employment Statistics from Stationary Equilibrium

Notes: (i) Entries are in per cent; (ii) Entries in the data column are taken from Davis and Haltiwanger [8]. 
weighted entry and exit rates are $0.2 \%$ higher and $0.33 \%$ lower, respectively, than the values reported by Davis and Haltiwanger $[8]^{7}$.

Although the model's implied statistics do not exactly match the statistics from the US manufacturing sector, they seem reasonably close. This gives us some confidence that the simulations we present in the next section have empirical relevance.

\subsection{Employment Fluctuations}

The examples we describe in this subsection are differentiated by assumptions regarding the forcing process for the wage rate and assumptions regarding the specification of creation costs. Consider the wage process first. The law of motion for the wage is chosen so that the $\log$ of the wage resembles a first order autoregression with an unconditional standard deviation of $1 \%$. In particular, the transition matrix, $\Pi$, is specified as

$$
\Pi=\left[\begin{array}{cc}
\frac{1+\rho_{w}}{2} & \frac{1-\rho_{w}}{2} \\
\frac{1-\rho_{w}}{2} & \frac{1+\rho_{w}}{2}
\end{array}\right],
$$

where $\left|\rho_{w}\right|<1$ is the autocorrelation coefficient, and the two wage levels are given by

$$
W^{h}=\exp (0.01) \text { and } W^{l}=\exp (-0.01)
$$

We explore the implications of auto-correlated wages, $\rho_{w}=0.9$, and i.i.d. wages, $\rho_{w}=0$.

Now consider the assumptions regarding job creation costs. In section 2 these costs were assumed to be invariant to the current wage. ${ }^{8}$ If job creation activity is labor intensive, then this may be a poor assumption since it would suggest that creation costs should be closely tied to the wage. This invariance plays a crucial role in the development of our intuition, so it is sensible to explore how it influences our results. To do so, in addition to the case of constant creation costs we explore versions of our model in which creation costs are proportional to the current wage. In these cases creation costs are assumed to be equal

\footnotetext{
${ }^{7}$ The employment weighted entry and exit rates are the employment gains at entering establishments and the employment losses at exiting establishments, divided by total manufacturing employment.

${ }^{8}$ It may be helpful at this point to think of the output price, the wage, and the job creation cost as being measured relative to the cost of creating an establishment, $\kappa$.
} 
$\%$ Change in Intervention Schedules

Constant Creation Costs

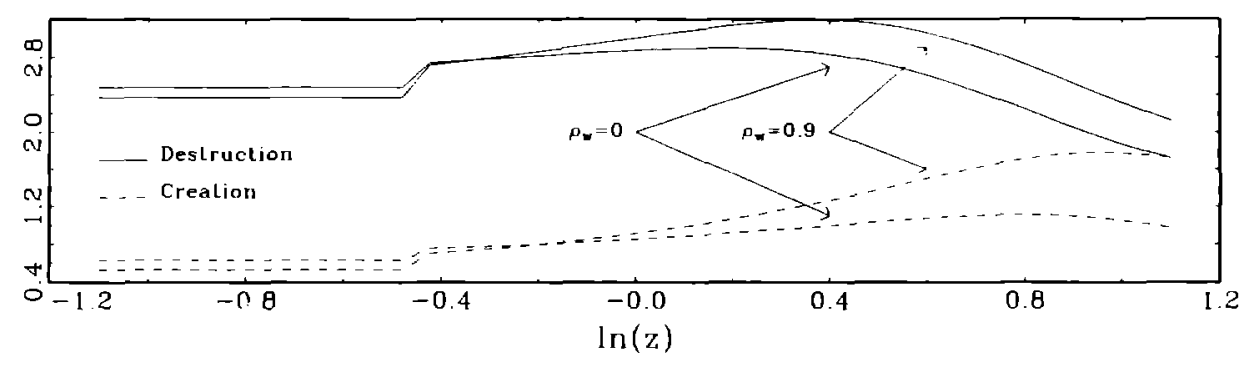

Variable Creation Costs

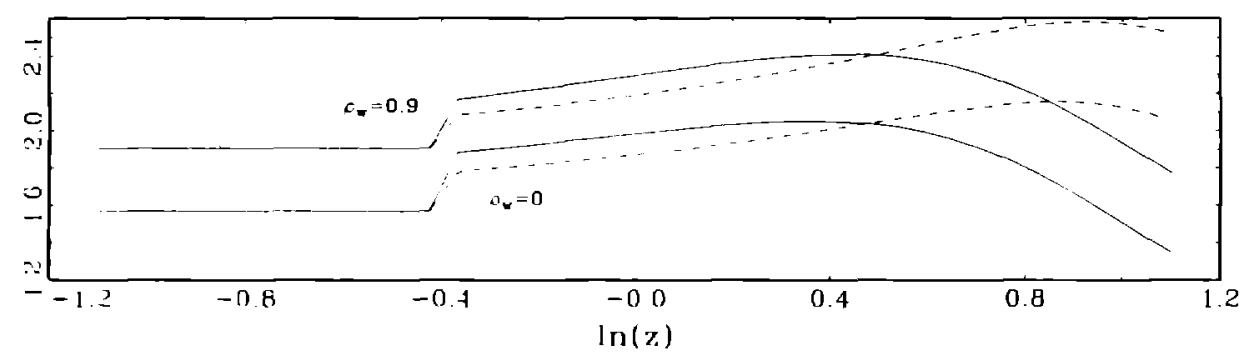

Figure 4: Changes in Job Creation and Destruction Schedules

to $\tau W_{t}$ in each period $t$.

Before studying the simulation results it is helpful to confirm that adding job creation costs to the establishments' technology dampens the employment responses of job creating establishments to changes in $W_{t}$. Figure 4 plots the differences between the job creation and destruction schedules in the two states. The solid lines of each panel plot the log of the destruction schedule in the low wage state minus the log of the destruction schedule in the high wage state and the dashed lines plot the difference between the creation schedules in the two states. The top panel pertains to the examples in which job creation costs are constant, and the bottom panel pertains to the examples where job creation costs are a constant fraction of the current wage.

Consistent with our intuition, when the job creation cost is constant the job destruction schedule is considerably more volatile than the job creation schedule. Regardless of the degree of serial correlation in the wage, the job destruction schedule changes about $2.5 \%$ more than 
the job creation schedule when the wage changes. Notice that an establishment's response to a change in the wage depends on its current productivity. For those establishments falling below the exit threshold, their employment decisions are static. That is, their employment decisions are those from the model with $\beta=0$. For those establishments above the exit threshold, dynamic considerations become important. These considerations appear to raise and then lower their responses to a change in the wage as their productivity increases. Finally, serial correlation in the wage appears to amplify the responses for establishments above the exit threshold but has little effect on those establishment about to exit. ${ }^{9}$

In the lower panel of figure 4 we see that the job creation and destruction schedules respond by roughly equal amounts to a wage change, regardless of the degree of serial correlation in the wage. The dynamic effects on the shapes of the schedules evident in the top panel are evident here also and these dynamic effects appear to be strong relative to the purely static effect emphasized in the development of our intuition. As in the constant cost case, adding wage persistence appears to amplify the response of the schedules for higher productivity establishments.

We conclude from analyzing figure 4 that the model's behavior depends in important navs on the specification for job creation costs. In the US economy, job creation probably requires some labor input. Thus creation costs will likely vary with the wage. On the other hand, the cost's elasticity with respect to the wage will be less than one if job creation requires some other input whose price has little correlation with the wage. If we want to think of the wage in the current model as governing production workers and job creation costs being associated with the effort of management employees, then to the extent that management remuneration is uncorrelated with the wages of production workers it may make sense to assume that creation costs do not vary one-for-one with wages. An empirically reasonable specification for job creation costs probably lies somewhere between the two extremes of zero and unit elasticity we consider here.

We now examine whether the differential volatility in the job creation and destruction schedules gives rise to differential volatility in job creation and destruction rates. In addition,

\footnotetext{
${ }^{9}$ The fact that wage autocorrelation influences the response of establishments below the exit threshold reflects the difference in the equilibrium response of the price level across the two cases.
} 
Volatility Statistics

\begin{tabular}{|l|l|cccc|}
\cline { 3 - 6 } \multicolumn{2}{c|}{} & \multicolumn{3}{c}{$\tau=1 / 2$} & \multicolumn{2}{c|}{$\tau=W_{t} / 2$} \\
\hline Volatility Statistic & Data & $\rho=0.9$ & $\rho=0$ & $\rho=0.9$ & $\rho=0$ \\
\hline Creation & 0.86 & 0.10 & 0.17 & 0.11 & 0.30 \\
Destruction & 1.71 & 1.50 & 1.60 & 1.00 & 0.60 \\
Growth & 2.24 & 2.00 & 2.41 & 1.82 & 1.53 \\
Reallocation & 1.67 & 1.40 & 1.06 & 0.60 & 0.50 \\
\hline
\end{tabular}

Note: The statistic for Creation is standard deviation in per cent. The other statistics are reported as ratios of standard deviations relative to the standard deviation of Creation.

\section{Co-movement Statistics}

\begin{tabular}{|l|r|rrrr|}
\cline { 4 - 6 } \multicolumn{1}{c|}{} & \multicolumn{3}{c|}{$\tau=1 / 2$} & \multicolumn{2}{c|}{$\tau=W_{t} / 2$} \\
Correlation & Data & $\rho=0.9$ & $\rho=0$ & $\rho=0.9$ & $\rho=0$ \\
\hline Creation, Destruction & -0.33 & -0.40 & -0.77 & -0.79 & -0.90 \\
Growth, Reallocation & -0.51 & -0.43 & -0.61 & -0.02 & 0.75 \\
Growth, Creation & 0.70 & 0.75 & 0.91 & 0.94 & 0.99 \\
Growth, Destruction & -0.91 & -0.90 & -0.97 & -0.95 & -0.96 \\
Reallocation, Creation & 0.27 & 0.27 & -0.23 & 0.31 & 0.85 \\
Reallocation, Destruction & 0.82 & 0.77 & 0.79 & 0.34 & -0.55 \\
\hline
\end{tabular}

Table 3: Employment Statistics in the Dynamic Economies

we examine several other employment flow statistics to evaluate the overall performance of our model. Table 3 reports measures of volatility and co-movement for rates of job creation, job destruction, job growth, and job reallocation as defined by Davis and Haltiwanger [8], for each of the four specifications we consider. ${ }^{10}$ The first panel of the table indicates overall employment volatility, as measured by the standard deviation of creation, as well as the relative volatility of the remaining variables, as measured by the indicated variable's standard deviation divided by the standard deviation of creation. The second panel indicates correlation coefficients for all possible pairwise combinations of the variables of interest.

Consider the top panel. Notice first that the constant creation cost examples replicate the empirical observation that job destruction is more variable than job creation. This is

\footnotetext{
${ }^{10}$ The statistics reported in table 3 are based on simulating the model for 1100 periods, beginning from the steady state distribution of establishments. We discarded the first 100 observations and used the remaining observations in our calculations.
} 
in keeping with the intuition developed above. The failure of the variable creation cost examples along this dimension reflects our previous observation that the job creation and destruction schedules in these cases respond by proportionally similar amounts when the wage changes.

The other statistics in this panel suggest that the constant creation cost version of the model has other desirable properties. In particular, regardless of the degree of serial correlation in the wage, this version of the model is able to account for the relative volatilities of the employment flow variables. Increasing the degree of serial correlation seems to improve the empirical performance in terms of the magnitudes of the relative volatility statistics. The variable cost examples are less successful in terms of accounting for relative volatilities. Finally, the main drawback of all these examples is that they imply too little overall volatility. Reducing serial correlation in the wage appears to improve the performance of the model along this dimension regardless of whether creation costs are variable or not.

Now consider the lower panel of correlations. The performance of the constant creation costs, $\rho=0.9$ version of the model is seen to be quite strong here as well. The signs of the six correlations are correct and the magnitudes do not appear to be very far off their empirical values either. It seems reasonable to conclude that the overall performance of this version of the model is good - the addition of job creation costs has the potential of accounting for more than just the fact that job destruction is more volatile than job creation. Reducing serial correlation in the wage in the constant cost case harms the model's comovement implications. In particular, when $\rho=0$ the model predicts counterfactually that job creation is negatively correlated with job reallocation. Finally, the specifications with variable creation costs perform poorly in terms of co-movement, just as they do with respect to relative volatilities.

At this point we should caution the reader by noting that the statistics in table 3 do not reflect entirely independent features of the data. We have already pointed out (in the introduction) that the relative volatility of destruction versus creation determines the sign of the correlation between job growth and reallocation. The algebraic identities linking creation and destruction with growth and reallocation imply other connections between the 
statistics. ${ }^{11}$ However, we do not believe this fact diminishes the overall impression that the constant creation cost, $\rho=0.9$ version of the model does remarkably well at accounting for the evidence on employment flows.

\section{Discussion}

The simulations described in the previous section confirm that the presence of asymmetric employment adjustment costs at the establishment level can lead to asymmetries in aggregate gross job flows. Of course, the presence of such costs is not the only available explanation for this phenomenon. In this section we conclude by describing how our work relates to other attempts to account for the evidence on job creation and destruction. Recall from the introduction that the observation of countercyclical job reallocation is equivalent to the observation that job destruction is more volatile than job creation. The discussion below considers papers which share our focus on the variability of job creation and destruction.

To begin with. consider Caballero [2]. He observed that asymmetric employment adjustment costs at the establishment level need not imply aggregate asymmetries. His explanation for the aggregate asymmetries relies on assuming that aggregate shocks are asymmetrically distributed. Since we consider only symmetrically distributed aggregate shocks, we establish that the aggregate asymmetries in employment flows may have nothing to do with the pattern of aggregate shocks and may be purely reflective of features of the microeconomy.

Another explanation of aggregate employment asymmetries is provided by Caballero and Hammour [3]. They construct a partial equilibrium model where jobs embody technological progress. The key assumptions in their model are that the costs of creating a job are increasing in the aggregate volume of job creation, while the costs of destroying a job are invariant to the aggregate volume of job destruction. Not surprisingly these assumptions lead to a decrease in the relative volatility of aggregate job creation. Our analysis differs in that we assume asymmetric employment adjustment costs at the establishment level rather than at the aggregate level.

\footnotetext{
${ }^{11}$ Simple calculations reveal the following connections. If creation and destruction are negatively correlated then (i) growth and creation are positively correlated, (ii) growth and destruction are negatively correlated, (iii) reallocation is less variable than growth, and (iv) growth is more variable than destruction.
} 
Finally, Foote [10] studies an $(S, s)$ model in which the trend growth rate in industry employment determines the volatility of job creation relative to that of job destruction. In his model, industry decline leads to the bunching of establishments near their job destruction points so that aggregate disturbances have a disproportionate impact on job destruction. An essential assumption in his analysis is that the decline in industry employment is carried out by lowering average establishment size while leaving the number of establishments constant. Our analysis clarifies when this is, and is not, a reasonable assumption. In our framework, if the source of industry decline is a reduction in demand, it will be accommodated by a fall in entry, not a decrease in average establishment size. However, average establishment size will decline if the source of the trend is an increase in the wage rate. 


\section{A. The Transition Rule}

In this appendix we present the transition rule for $G_{t}$. To do so we make use of several definitions. First, define two critical productivity levels, $\underline{z}_{t}^{*}$ and $\bar{z}_{t}^{*}$,

$$
\underline{z}_{t}^{*}=x_{t}\left(\underline{n}_{t}\left(\underline{z}_{t}^{*}\right)\right) \text { and } \bar{z}_{t}^{*}=x_{t}\left(\bar{n}_{t}\left(\bar{z}_{t}^{*}\right)\right) \text {. }
$$

Second, define $\underline{n}_{t}^{*}$ and $\bar{n}_{t}^{*}$ as

$$
\underline{n}_{t}^{*}=\underline{n}_{t}\left(\underline{z}_{t}^{*}\right) \text { and } \bar{n}_{t}^{*}=\bar{n}_{t}\left(\bar{z}_{t}^{*}\right)
$$

The functions $\underline{n}_{t}\left(z_{t}\right)$ and $\bar{n}_{t}\left(z_{t}\right)$ intersect the exit threshold $x_{t}\left(n_{t}\right)$ at the points $\left(\underline{z}_{t}^{*}, \underline{n}_{t}^{*}\right)$ and $\left(\bar{z}_{t}^{*}, \bar{n}_{t}^{*}\right)$, respectively. Third, define $\underline{h}_{t}\left(n_{t}\right)$ and $\bar{h}_{t}\left(n_{t}\right)$ to be the inverse functions of $\underline{n}_{t}\left(z_{t}\right)$ and $\bar{n}_{t}\left(z_{t}\right)$, respectively. Finally, we use $\phi\left(z_{t+1} \mid z_{t}\right)$ to denote the conditional density of $z_{t+1}$ given $z_{t}$.

To present the transition rule for $G_{t}\left(z_{t}, n_{t}\right)$, it is easiest to consider each of the three functions, $\bar{G}_{t}\left(z_{t}\right), \underline{G}_{t}\left(z_{t}\right)$, and $G^{m}\left(z_{t}, n_{t}\right)$, separately. We begin by describing the third of these functions. Any establishment with employment between the schedules defined by $\underline{n}_{t+1}\left(z_{t+1}\right)$ and $\bar{n}_{t+1}\left(z_{t+1}\right)$ employs the same number of workers as it did in the previous period. Therefore, to find the 'number' of establishments with productivity $z_{t+1}$ which employ $n_{t+1}$ workers, we need to add the 'probabilities' of all establishments with previous employment $n_{t+1}$ having productivity equal to $z_{t+1}$. Consider three separate cases. First, if $n_{t+1} \geq \bar{n}_{t}^{*}$, then

$$
\begin{aligned}
G_{t+1}^{m}\left(z_{t+1}, n_{t+1}\right)= & \int_{\bar{h}_{t}\left(n_{t+1}\right)}^{\underline{h}_{t}\left(n_{t+1}\right)} G_{t}^{m}\left(z_{t}, n_{t+1}\right) \phi\left(z_{t+1} \mid z_{t}\right) d z_{t} \\
& +\phi\left(z_{t+1} \mid \underline{h}_{t}\left(n_{t+1}\right)\right) \underline{G}_{t}\left(\underline{h}_{t}\left(n_{t+1}\right)\right) \\
& +\phi\left(z_{t+1} \mid \bar{h}_{t}\left(n_{t+1}\right)\right) \bar{G}_{t}\left(\bar{h}_{t}\left(n_{t+1}\right)\right) .
\end{aligned}
$$

The first term is the contribution of those between the employment rules in period $t$ with employment $n_{t+1}$ who remain there, the second term is the contribution of those who increased their employment during the previous period to $n_{t+1}$, and the final term is the contribution of those who decreased their employment during the previous period to $n_{t+1}$.

Second, if $\bar{n}_{t}^{*}>n_{t+1} \geq \underline{n}_{t}^{*}$, then

$$
\begin{aligned}
G_{t+1}^{m}\left(z_{t+1}, n_{t+1}\right)= & \int_{x_{t}\left(n_{t+1}\right)}^{\underline{h}_{t}\left(n_{t+1}\right)} G_{t}^{m}\left(z_{t}, n_{t+1}\right) \phi\left(z_{t+1} \mid z_{t}\right) d z_{t} \\
& +\phi\left(z_{t+1} \mid \underline{h}_{t}\left(n_{t+1}\right)\right) \underline{G}_{t}\left(\underline{h}_{t}\left(n_{t+1}\right)\right) .
\end{aligned}
$$

The the differences between equations 10 and 11 reflect the exit of low productivity establishments.

Finally, if $\underline{n}_{t}^{*}>n_{t+1}$, then

$$
G_{t+1}^{m}\left(z_{t+1}, n_{t+1}\right)=0 .
$$

This is because all establishments with employment less than $\underline{n}_{t}^{*}$ exit.

To determine $\bar{G}_{t+1}\left(z_{t+1}\right)$, it is useful to consider the same three cases. First, if $\bar{n}_{t+1}\left(z_{t+1}\right) \geq$ 
$\bar{n}_{t}^{*}$ then

$$
\begin{aligned}
\bar{G}_{t+1}\left(z_{t+1}\right)= & \int_{\bar{n}_{t+1}\left(z_{t+1}\right)}^{\infty} \int_{\bar{h}_{t}\left(n_{t}\right)}^{\underline{h}_{t}\left(n_{t}\right)} G_{t}^{m}\left(z_{t}, n_{t}\right) \phi\left(z_{t+1} \mid z_{t}\right) d z_{t} d n_{t} \\
& +\int_{\bar{h}_{t}\left(\bar{n}_{t+1}\left(z_{t+1}\right)\right)}^{\infty} \bar{G}_{t}\left(z_{t}\right) \phi\left(z_{t+1} \mid z_{t}\right) d z_{t} \\
& +\int_{\underline{h}_{t}\left(\bar{n}_{t+1}\left(z_{t+1}\right)\right)}^{\infty} \underline{G}_{t}\left(z_{t}\right) \phi\left(z_{t+1} \mid z_{t}\right) d z_{t} .
\end{aligned}
$$

Next, if $\bar{n}_{t}^{*}>\bar{n}_{t+1}\left(z_{t+1}\right) \geq \underline{n}_{t}^{*}$, then

$$
\begin{aligned}
\bar{G}_{t+1}\left(z_{t+1}\right)= & \int_{\bar{n}_{i}^{*}}^{\infty} \int_{\bar{h}_{t}\left(n_{t}\right)}^{\underline{h}_{t}\left(n_{t}\right)} G_{t}^{m}\left(z_{t}, n_{t}\right) \phi\left(z_{t+1} \mid z_{t}\right) d z_{t} d n_{t} \\
& +\int_{\bar{n}_{t+1}\left(z_{t+1}\right)}^{\bar{n}_{i}^{*}} \int_{x_{t}\left(n_{t}\right)}^{\underline{h}_{t}\left(n_{t}\right)} G_{t}^{m}\left(z_{t}, n_{t}\right) \phi\left(z_{t+1} \mid z_{t}\right) d z_{t} d n_{t} \\
& +\int_{\bar{z}_{i}^{*}}^{\infty} \bar{G}_{t}\left(z_{t}\right) \phi\left(z_{t+1} \mid z_{t}\right) d z_{t} \\
& +\int_{\underline{h}_{t}\left(\bar{n}_{t+1}\left(z_{t+1}\right)\right)}^{\infty} \underline{G}_{t}\left(z_{t}\right) \phi\left(z_{t+1} \mid z_{t}\right) d z_{t} .
\end{aligned}
$$

Finally, if $\underline{n}_{t}^{*}>\bar{n}_{t+1}\left(z_{t+1}\right)$, then

$$
\begin{aligned}
\bar{G}_{t+1}\left(z_{t+1}\right)= & \int_{\bar{n}_{t}^{*}}^{\infty} \int_{\bar{h}_{t}\left(n_{t}\right)}^{\underline{h}_{t}\left(n_{t}\right.} G_{t}^{m}\left(z_{t}, n_{t}\right) \phi\left(z_{t+1} \mid z_{t}\right) d z_{t} d n_{t} \\
& +\int_{\underline{n}_{t}^{*}}^{\bar{n}_{t}^{*}} \int_{x_{t}\left(n_{t}\right)}^{\underline{h}_{t}\left(n_{t}\right.} G_{t}^{m}\left(z_{t}, n_{t}\right) \phi\left(z_{t+1} \mid z_{t}\right) d z_{t} d n_{t} \\
& +\int_{\bar{z}_{t}^{*}}^{\infty} \bar{G}_{t}\left(z_{t}\right) \phi\left(z_{t+1} \mid z_{t}\right) d z_{t} \\
& +\int_{\underline{z}_{t}^{*}}^{\infty} G_{t}\left(z_{t}\right) \phi\left(z_{t+1} \mid z_{t}\right) d z_{t} .
\end{aligned}
$$
then

Once again, consider the same three cases to determine $\underline{G}_{t+1}\left(z_{t+1}\right)$. If $\underline{n}_{t+1}\left(z_{t+1}\right) \geq \bar{n}_{t}^{*}$,

$$
\begin{aligned}
G_{t+1}\left(z_{t+1}\right)= & \int_{\bar{n}_{t}^{*}}^{\underline{n}_{t+1}\left(z_{t+1}\right)} \int_{\bar{h}_{t}\left(n_{t}\right)}^{\underline{h}_{t}\left(n_{t}\right)} G_{t}^{m}\left(z_{t}, n_{t}\right) \phi\left(z_{t+1} \mid z_{t}\right) d z_{t} d n_{t} \\
& +\int_{\underline{n}_{t}^{*}}^{\bar{n}_{t}^{*}} \int_{x_{t}\left(n_{t}\right)}^{\underline{h}_{t}\left(n_{t}\right)} G_{t}^{m}\left(z_{t}, n_{t}\right) \phi\left(z_{t+1} \mid z_{t}\right) d z_{t} d n_{t} \\
& +\int_{\bar{z}_{t}^{*}}^{z_{t+1}} \bar{G}_{t}\left(z_{t}\right) \phi\left(z_{t+1} \mid z_{t}\right) d z_{t} \\
& +\int_{\underline{z}_{t}^{*}}^{z_{t+1}} \underline{G}_{t}\left(z_{t}\right) \phi\left(z_{t+1} \mid z_{t}\right) d z_{t} \\
& +B_{t+1} \lambda\left(z_{t+1}\right) .
\end{aligned}
$$

The last term of this expression reflects the contribution of new entrants, who always increase their employment above its previous level, zero. 
If $\bar{n}_{t}^{*}>\underline{n}_{t+1}\left(z_{t+1}\right) \geq \underline{n}_{t}^{*}$, then

$$
\begin{aligned}
\underline{G}_{t+1}\left(z_{t+1}\right)= & \int_{\underline{\underline{n}}_{t}^{*}}^{\underline{n}_{t+1}\left(z_{t+1}\right)} \int_{x_{\mathfrak{t}}\left(n_{t}\right)}^{\underline{h}_{t}\left(n_{t}\right)} G_{t}^{\mathrm{m}}\left(z_{t}, n_{t}\right) \phi\left(z_{t+1} \mid z_{t}\right) d z_{t} d n_{t} \\
& +\int_{\underline{z}_{t}^{*}}^{z_{t+1}} \underline{G}_{t}\left(z_{t}\right) \phi\left(z_{t+1} \mid z_{t}\right) d z_{t} \\
& +B_{t+1} \lambda\left(z_{t+1}\right) .
\end{aligned}
$$

Finally, if $\underline{n}_{t}^{*}>\underline{n}_{t+1}\left(z_{t+1}\right)$, then

$$
\underline{G}_{t+1}\left(z_{t+1}\right)=B_{t+1} \lambda\left(z_{t+1}\right)
$$

\section{B. The Case of Costless Job Creation}

In this appendix we characterize analytically a version of the model with costless job creation. This example is helpful since it illustrates a case where the assumption of strictly positive entry, which underlies our strategy for computing equilibria in the more general version of the model, is guaranteed to hold.

Here we simplify the model of the main text in two ways: (1) we set $\tau=0$; and (2) we assume unit elastic demand, $\gamma=-1$. To begin with, note that if job creation is costless current employment will be chosen to maximize static establishment returns,

$$
n_{t}=\left(\frac{W_{t}}{\alpha z_{t} P_{t}}\right)^{\frac{1}{\alpha-1}}
$$

This implies a one-to-one mapping between productivity levels and employment so keeping track of the joint distribution of employment and productivity is pointless. Thus, we write the industry's state variable as $G_{t}\left(z_{t}\right)$, which describes the measure of productivity over all establishments.

Theorems 2, 3, and 4 of Hopenhayn [11] guarantee that the model with zero adjustment costs has a unique stationary equilibrium and that stationary equilibrium entry and exit are strictly positive. ${ }^{12}$ Suppose the industry's initial measure over productivity levels is the stationary equilibrium measure, $G^{*}\left(z_{t}\right)$, and that the wage in the current period is $W_{t}$ instead of the value used to compute the stationary equilibrium, $W^{*}$. In this case static profits of an establishment with productivity $z_{t}$ are

$$
\pi_{t}\left(z_{t}\right)=\left(P_{t} z_{t}\right)^{\frac{1}{1-\alpha}} W_{t}^{\frac{\alpha}{\alpha-1}}\left(\alpha^{\frac{\alpha}{1-\alpha}}-\alpha^{\frac{1}{1-\alpha}}\right) .
$$

Now, choose a price $P_{t}$ so that $\pi_{t}\left(z_{t}\right)$ equals its stationary equilibrium counterpart,

$$
P_{t}=P^{*}\left(\frac{W_{t}}{W^{*}}\right)^{\alpha}
$$

At this price profits of establishments as a function of productivity are the same as in the

\footnotetext{
${ }^{12}$ Our model satisfies conditions U1 and U2 of Hopenhayn [11].
} 
stationary equilibrium. Suppose the competitive equilibrium output price is given by (19) in each period $t$. In this case, since one period returns are the same as in the stationary equilibrium, the establishment owner's value function and exit decision rule will be unchanged by the addition of aggregate uncertainty. If the value function is unchanged from the stationary equilibrium, the free entry condition must still be satisfied. Therefore, if $B^{*}$ new establishments begin production during date $t$, the measure over productivity in that date will equal $G^{*}\left(z_{t}\right)$.

We now examine whether $P_{t}$ as given by (19) is a market clearing price. Our task is to verify that aggregate demand equals aggregate supply at each date $t$ with this price. Consider first aggregate supply. If $P_{t}$ is the prevailing price and the current wage equals $W_{t}$, the output of a single establishment with productivity $z_{t}$ is

$$
\begin{aligned}
q_{t}\left(z_{t}\right) & =z_{t}^{\frac{1}{1-\alpha}}\left(\frac{\alpha P_{t}}{W_{t}}\right)^{\frac{\alpha}{1-\alpha}} \\
& =z_{t}^{\frac{1}{1-\alpha}}\left(\alpha \frac{P^{*}}{W^{*}}\right)^{\frac{\alpha}{1-\alpha}}\left(\frac{W_{t}}{W^{*}}\right)^{-\alpha} \\
& =q^{*}\left(z_{t}\right)\left(\frac{W_{t}}{W^{*}}\right)^{-\alpha},
\end{aligned}
$$

where $q^{*}\left(z_{t}\right)$ is the output of an establishment with productivity level $z_{t}$ in the stationary equilibrium. Therefore, aggregate out put is given by

$$
\begin{aligned}
Q_{t} & =\int q_{t}\left(z_{t}\right) G^{*}\left(z_{t}\right) d z_{t} \\
& =\int q^{*}\left(z_{t}\right)\left(\frac{W_{t}}{W^{*}}\right)^{-\alpha} G^{*}\left(z_{t}\right) d z_{t} \\
& =Q^{*}\left(\frac{W_{t}}{W^{*}}\right)^{-\alpha},
\end{aligned}
$$

where we have assumed that $B^{*}$ new establishments begin production at every date $t$. Also, $Q^{*}$ is the stationary equilibrium aggregate supply. Now consider aggregate demand. The aggregate quantity demanded at the price $P_{\ell}$ is

$$
\begin{aligned}
P_{t}^{\gamma} & =P^{*-1}\left(\frac{W_{t}}{W^{*}}\right)^{-\alpha} \\
& =Q^{*}\left(\frac{W_{t}}{W^{*}}\right)^{-\alpha}
\end{aligned}
$$

Thus, the price given in (19) is indeed a market clearing price for every date $t$. Note that the equilibrium we have constructed is for an initial measure of establishments across productivity levels equal to the stationary equilibrium measure. In this special case, it is clear that the assumption of positive entry in every possible state is valid since $B^{*}$ is guaranteed to be positive. 


\section{References}

[1] Anderson, Patricia and Bruce Meyer. 1994. The Extent and Consequences of Job Turnover. Brookings Papers on Economic Activity, Microeconomics, pp. 177-236.

[2] Caballero, Ricardo J. A Fallacy of Composition. American Economic Review, 82(5), 1279-1292.

[3] Caballero, Ricardo J. and Mohamad L. Hammour. 1994. The Cleansing Effect of Recessions. American Economic Review, 84(5), 1350-1368.

[4] Caballero, Ricardo J. and Mohamad L. Hammour. 1994. On the Timing and Efficiency of Creative Destruction. Unpublished Working Paper, MIT.

[5] Campbell, Jeffrey. 1995. Entry, Exit, Technology and Business Cycles. Unpublished Northwestern University dissertation.

[6] Campbell, Jeffrey R. and Kenneth N. Kuttner. 1996. Macroeconomic Effects of Employment Reallocation. Forthcoming in Carnegie-Rochester Conference on Public Policy, Spring 1995.

[7] Davis, Steven J. and John Haltiwanger. 1990. Gross Job Creation and Destruction: Microeconomic Evidence and Macroeconomic Implications, in Olivier Jean Blanchard and Stanley Fischer (eds), NBER Macroeconomics Annual

[8] Davis, Steven J. and John Haltiwanger. 1992. Gross Job Creation, Gross Job Destruction, and Employment Reallocation. Quarterly Journal of Economics, 107(3), 819-863.

[9] Davis, Steven J. and John Haltiwanger. 1994. Driving Forces and Employment Fluctuations: New Evidence and Alternative Interpretations. Unpublished Working Paper, University of Maryland.

[10] Foote, Christopher L. 1995. Trend Employment Growth and the Bunching of Job Creation and Destruction. Unpublished Working Paper, University of Michigan.

[11] Hopenhayn, Hugo A. 1992. Entry, Exit, and Firm Dynamics in Long Run Equilibrium. Econometrica, 60(5), 1127-1150.

[12] Hopenhayn, Hugo A. and Richard Rogerson. 1993. Job Turnover and Policy Evaluation: A General Equilibrium Analysis. Journal of Political Economy, 101(5), 915-938.

[13] Mortensen, Dale T. and Christopher A. Pissarides. 1994. Job Creation and Job Destruction in the Theory of Unemployment. Review of Economic Studies, 61, 1121-1142.. 